\title{
Microsystem with integrated capillary leak to mass spectrometer for high sensitivity temperature programmed desorption
}

\author{
Quaade, Ulrich; Jensen, Søren; Hansen, Ole
}

Published in:

Review of Scientific Instruments

Link to article, DOI:

$10.1063 / 1.1791851$

Publication date:

2004

Document Version

Publisher's PDF, also known as Version of record

Link back to DTU Orbit

Citation (APA):

Quaade, U., Jensen, S., \& Hansen, O. (2004). Microsystem with integrated capillary leak to mass spectrometer for high sensitivity temperature programmed desorption. Review of Scientific Instruments, 75(10), 3345-3347. https://doi.org/10.1063/1.1791851

\section{General rights}

Copyright and moral rights for the publications made accessible in the public portal are retained by the authors and/or other copyright owners and it is a condition of accessing publications that users recognise and abide by the legal requirements associated with these rights.

- Users may download and print one copy of any publication from the public portal for the purpose of private study or research.

- You may not further distribute the material or use it for any profit-making activity or commercial gain

- You may freely distribute the URL identifying the publication in the public portal 


\title{
Microsystem with integrated capillary leak to mass spectrometer for high sensitivity temperature programmed desorption
}

\author{
Ulrich J. Quaade ${ }^{\text {a) }}$ \\ ICAT, Department of Physics, Technical University of Denmark, Building 312, DK-2800 Kgs. \\ Lyngby, Denmark \\ Søren Jensen and Ole Hansen \\ MIC-Department of Micro- and Nanotechnology, Technical University of Denmark, Bldg. 345E, \\ DK-2800 Kgs. Lyngby, Denmark
}

(Received 21 April 2004; accepted 29 June 2004; published 24 September 2004)

\begin{abstract}
Temperature programmed desorption (TPD) is a method for obtaining information about quantities and binding properties of adsorbed species on a surface. A microfabricated flow system for TPD with an integrated capillary leak to a mass spectrometer is presented. The use of an integrated capillary leak minimizes dead volumes in the system, resulting in increased sensitivity and reduced response time. These properties make the system ideal for TPD experiments in a carrier gas. With $\mathrm{CO}$ desorbing from platinum as model system, it is shown that $\mathrm{CO}$ desorbing in $10^{5} \mathrm{~Pa}$ of argon from as little as $0.5 \mathrm{~cm}^{2}$ of platinum foil gives a clear desorption peak. By using the microfabricated flow system, TPD experiments can be performed in a carrier gas with a sensitivity approaching that of TPD experiments in vacuum. (C) 2004 American Institute of Physics. [DOI: 10.1063/1.1791851]
\end{abstract}

\section{INTRODUCTION}

Microfabricated chemical reactors have been shown to offer a new framework for chemical production and investigation of chemical reactions with significant advantages over conventional instrumentation. ${ }^{1}$ Further, miniaturization can improve sensitivity in conditions, where small amounts of analytes are otherwise diluted below the detection limit in large scale systems.

Temperature programmed desorption is a widely used surface sensing technique for obtaining information about the amount and binding energies of adsorbed species on a surface. TPD experiments can be performed on wellcharacterized single crystal surfaces under ultra high vacuum (UHV) conditions where the desorbing atoms or molecules are directly detected by a mass spectrometer. ${ }^{2}$ Alternatively, desorption into a carrier gas at high pressure is possible. In this case, the atoms and molecules desorb into the carrier gas, which is subsequently analyzed. ${ }^{3}$ A monolayer of molecules on a flat nonporous surface desorbing into a carrier gas will usually be well below the detection limit, and the method is usually used to study high surface-area materials such as catalysts. Thus there is a gap between the two techniques: The UHV-TPD is well-controlled and has high sensitivity, but can only be used to measure desorption of chemisorbed molecules. Using TPD in a carrier gas, both adsorption and desorption can be measured as well as equilibrium properties between adsorbed molecules and molecules in the gas, but only on porous surfaces that are difficult to characterize in detail.

In the present work, microfabrication techniques are used to construct a gas flow microreactor with high surface-

${ }^{a)}$ Electronic mail: quaade@fysik.dtu.dk to-volume ratio, enabling TPD measurements on nonporous surfaces in a carrier gas. Initial measurements show that the system is capable of detecting $\mathrm{CO}$ desorbing from a $0.5 \mathrm{~cm}^{2}$ area of platinum in an argon carrier gas at a pressure of $10^{5} \mathrm{~Pa}$.

\section{MICROREACTOR SPECIFICATION AND FABRICATION}

$\mathrm{CO}$ desorption from platinum is used as test system. A saturated platinum surface of $10 \mathrm{~mm}^{2}$ contains about $10^{14}$ molecules of CO. One $\mathrm{mm}^{3}$ gas at $10^{5} \mathrm{~Pa}$ contains about $10^{16}$ molecules at $T=200^{\circ} \mathrm{C}$. Thus, a reactor with a volume of $1 \mathrm{~mm}^{3}$ containing platinum with a surface area of $10 \mathrm{~mm}^{2}$ will give a concentration of the desorbing molecules in the order of $1 \%$ if there is no flow in the reactor. Normally, the TPD measurements will be performed with a given flow of carrier gas in the reactor and the concentrations will decrease depending on the flow rate. Systems or reactors in the above dimension range can be fabricated using microfabrication techniques as seen for example in Ref. 4.

The chosen reactor layout is shown in Fig. 1. The narrow in- and outlet channels reduce diffusion in and out of the reactor volume at small flow rates. The reactor volume is $4 \mathrm{~mm}^{3}$, and in the bottom of the reactor volume, the platinum is placed as pieces of foil with total area of $50 \mathrm{~mm}^{2}$.

The interfacing to a microsystem is typically much bigger than the microsystem itself. The volume of the microreactor is much smaller than the gas volumes present in the inlet and outlet of the interfacing. This means that any change of the gas composition in the microreactor will be delayed and diluted in the outlet. The results of any subsequent analysis of the gas will be poor, and the advantage of using the microsystem will vanish. 

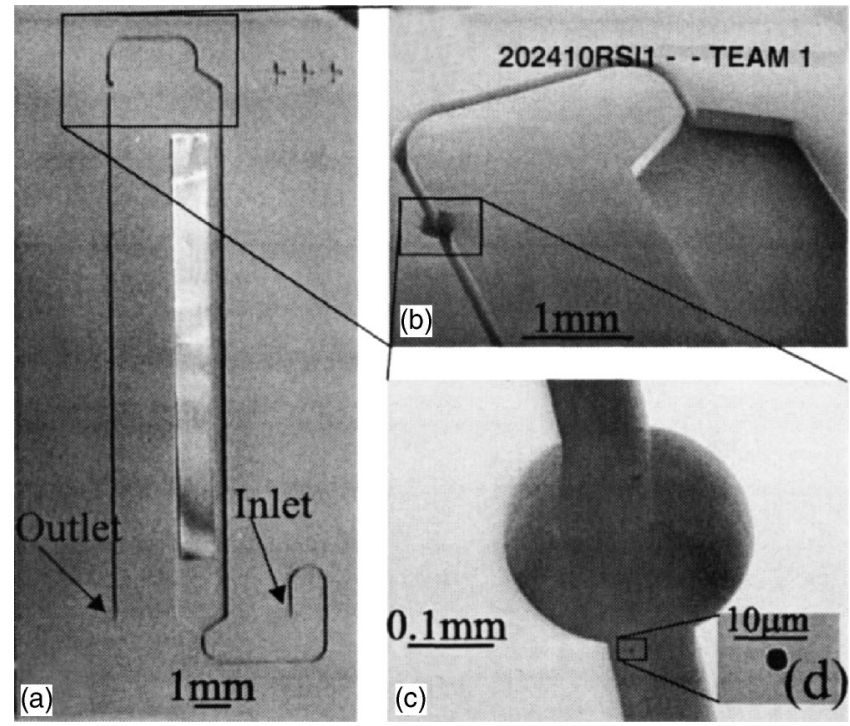

FIG. 1. Reactor layout: (a) Overview of the reactor showing inlet and outlet. The reactor chamber is $1.5 \mathrm{~mm}$ wide and $15 \mathrm{~mm}$ long. A piece of platinum foil is placed in the channel. The thin inlet and outlet channels are $100 \mu \mathrm{m}$ wide. (b) Magnification of the outlet of the reactor and the leak to the mass spectrometer. (c) Magnification of the leak to the mass spectrometer. (d) Magnification of the capillary.

Instead, the mass spectrometer has to sample the gas directly from the chip. In Ref. 4 this is done by placing a narrow quartz capillary leak ${ }^{5}$ in the outlet channel on the chip. In the present work, the capillary leak is fabricated directly in the silicon structure. This decreases the volume on the chip and simplifies the overall handling. Figures 1(c) and 1(d) shows the microfabricated capillary leak. The capillaries are $2-4 \mu \mathrm{m}$ in diameter and about $30-50 \mu \mathrm{m}$ long and go from the bottom of the outlet channel to the back of the chip. Characterization of the flow properties of the microfabricated capillaries is discussed in Ref. 6. Depending on the dimensions of the capillary and the pumping speed of the vacuum chamber, the pressure in the mass spectrometer typically reaches $10^{-7}-10^{-5}$ Torr when gas is leaking through the capillary.

The reactors are fabricated using a combination of UV photolithography and deep reactive ion etching. Deep reactive ion etching (DRIE) is a technique with which deep and narrow structures with vertical sidewalls can be etched in silicon. ${ }^{7}$

The fabrication sequence is shown in Fig. 2. The starting point is a $350 \mu \mathrm{m}$ thick silicon substrate. First, what will later become the substrate backside is covered with a $1.5 \mu \mathrm{m}$ thick layer of AZ5214 photosensitive, etch resistant polymer (photoresist). A pattern containing the capillary leak and inand outlet holes is then defined in the polymer using ultraviolet (UV) lithography, whereafter the holes are etched using DRIE. The depth of the narrow capillaries will define the reactor bottom thickness, and the maximum achievable depth is approximately $30-50 \mu \mathrm{m}$, limited by the removal rate of the polymer mask in the DRIE process. After etching the backside holes the polymer mask is removed in acetone. A $9.5 \mu \mathrm{m}$ thick layer of AZ4562 photoresist is then applied to the front side of the wafer, and a pattern containing the re-
1

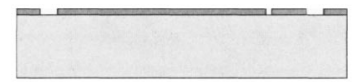

2

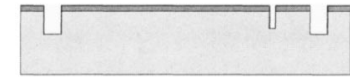

3

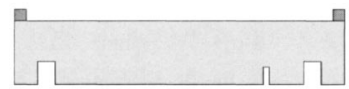

4

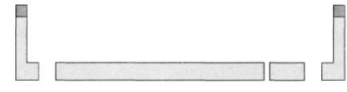

5

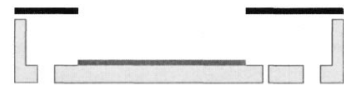

6

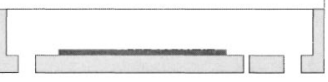

FIG. 2. Fabrication sequence for the microfabricated flow system: (1) Inlet, outlet and capillary leak are defined in photoresist; (2) etching of the inlet, outlet and capillary leak; (3) reactor channel is defined in photoresist; (4) etching of the reactor channel; (5) deposition of platinum through shadow mask (if this method is used); (6) reactor closed using anodic bonding.

actor structure is defined by UV lithography. The pattern is then etched using DRIE until it reaches the capillaries at a depth of approximately $300-320 \mu \mathrm{m}$.

After etching the reactor structures, a piece of platinum foil is placed in the reactor, and the reactor is closed with a piece of Pyrex using anodic bonding. Alternatively, a layer of platinum can be deposited on the bottom of the reactor through a shadow mask using electron beam evaporation. However, using this method a possible formation of platinum silicide at elevated temperatures should be considered.

The interfacing is shown in Fig. 3. The inlet and outlet holes and the capillary leak are matched by channels drilled in a block of aluminum. The aluminum block is connected through Swagelock fittings and tubing to mass flow controllers and the vacuum chamber containing the mass spectrometer. The reactor is heated by placing a piece of silicon on top of the reactor and heating it resistively by passing a current through it. The temperature is measured with a thermocouple mounted on the bottom of the reactor, and a feed-back algorithm implemented on a computer controls the heating power and the temperature. Temperature ramps up to $20^{\circ} \mathrm{C} / \mathrm{s}$ can be obtained.

A carrier gas of $99.9999 \%$ pure argon is used. The CO source is a mixture containing $1 \%{ }^{29} \mathrm{CO}$ in argon. The reason for using labeled $\mathrm{CO}$ in the experiment is to eliminate any risk that the measured $\mathrm{CO}$ signals are distorted by traces of nitrogen in the system. Both gasses are controlled using mass flow controllers with a range of $0.04-2 \mathrm{~mL} / \mathrm{min}$. The flow controllers leak slightly even when set at zero flow, and the gas flows are further controlled by a leak-free three-way valve that can switch between $\mathrm{CO}$ and pure argon.

With the described setup, basically no dead volume is

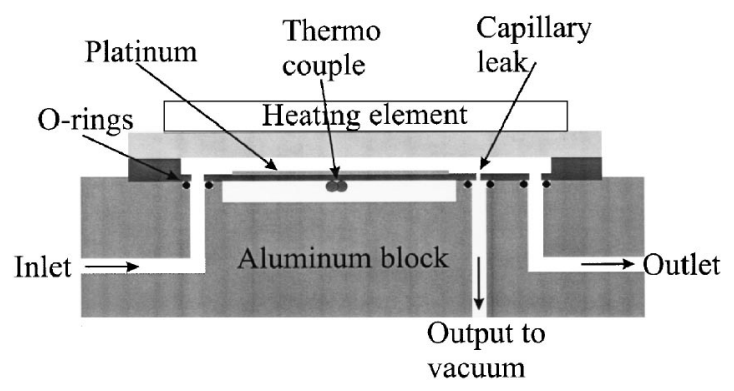

FIG. 3. Schematic diagram of the interfacing to the microfabricated reactor. 


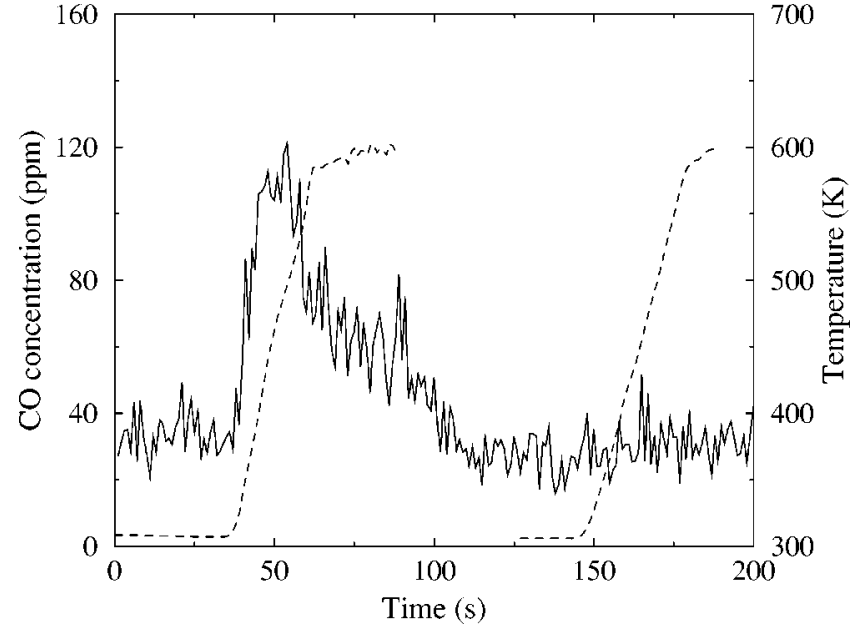

FIG. 4. TPD experiment. The CO concentration in the gas is shown as function of time while the temperature is ramped from room temperature to above $575 \mathrm{~K}$. The dashed curves show the temperature ramps. The temperature is not measured during cooling, but the cooling rate is similar to the heating rate. At the first ramp no $\mathrm{CO}$ is desorbed. At the second ramp on $\mathrm{CO}$ is left for desorption.

introduced, and the limitations in sensitivity and time resolution is determined by the reactor volume, the expansion time in vacuum, and the measurement time and sensitivity of the mass spectrometer.

\section{MEASUREMENTS}

In the experiments, the surface is first saturated with $\mathrm{CO}$ at room temperature by passing the $\mathrm{CO}$ containing gas mixture through the reactor for $10 \mathrm{~min}$. Second, the reactor is flushed with argon at $2 \mathrm{~mL} / \mathrm{min}$ for about $1 \mathrm{~min}$ until the ${ }^{29} \mathrm{CO}$ signals measured with the mass spectrometer stabilizes at the background level. The flow rate is then reduced and the temperature is ramped for desorption.

Figure 4 shows the concentration of ${ }^{29} \mathrm{CO}$ in an argon flow of $0.04 \mathrm{~mL} / \mathrm{min}$ when the temperature is ramped. At the first temperature ramp a clear signal of ${ }^{29} \mathrm{CO}$ is seen. As control a second temperature ramp is applied with no detection of ${ }^{29} \mathrm{CO}$.

The estimated amount of $\mathrm{CO}$ adsorbed on the $0.5 \mathrm{~cm}^{2}$ of platinum in the reactor at a maximum coverage of 0.7 (Ref. 8) is $7 \cdot 10^{14}$ molecules. The integrated amount of desorbed ${ }^{29} \mathrm{CO}$ in Fig. 4 is $7 \cdot 10^{13}$ molecules, which is only $10 \%$ of the expected. There are three likely reasons for that: (1) The platinum foil has not been cleaned in situ and the $\mathrm{CO}$ coverage might be considerably lower than expected. Usually, in situ cleaning consists of repeated cycles of oxidation in oxygen and reduction in hydrogen at temperatures above $400^{\circ} \mathrm{C}$ In the present setup the maximum temperature is limited to $200-300^{\circ} \mathrm{C}$ by the o-ring seals. However, the signals do increase slightly with oxidation/reduction cycles at these lower temperatures. (2) Traces of oxygen in the argon gas might react with $\mathrm{CO}$ on the surface at room temperature while the system is flushed prior to the TPD. Although a possibility, it is unlikely, since the argon gas used is certified oxygen free, and the signals do not seem to decrease with flushing time. (3) In the system used, it is not possible to heat

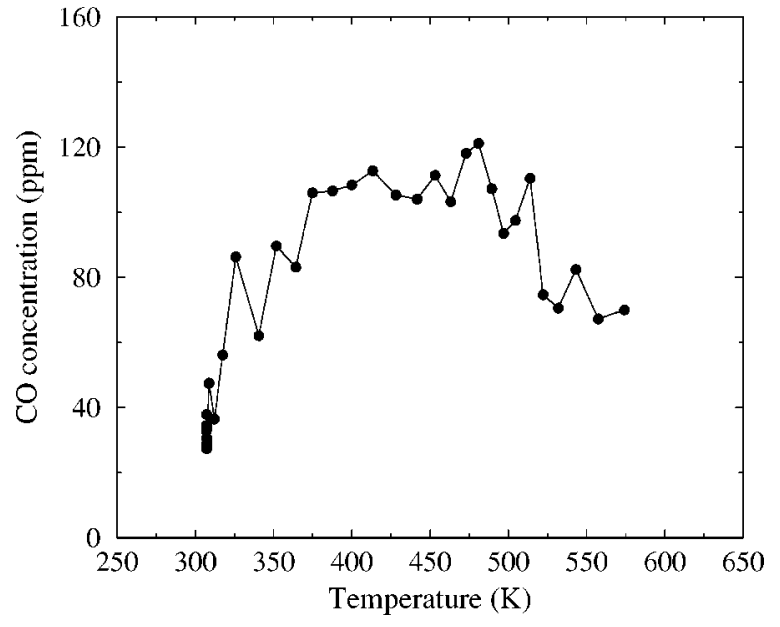

FIG. 5. CO desorption signal as function of temperature.

all parts of the vacuum chamber containing the mass spectrometer, and certainly some of the $\mathrm{CO}$ will adsorb on the stainless steel inner walls of the chamber. Most of the vacuum chamber is heated. but a few valves and the mass spectrometer itself cannot withstand elevated temperatures. It is not known how much $\mathrm{CO}$ will absorb, but with no heating the signals completely vanish. The effects cannot be quantified, but they can all be eliminated in an improved setup.

Figure 5 shows the ${ }^{29} \mathrm{CO}$ desorption as function of temperature. The desorption starts when the temperature begins to rise and is constant within the noise until $525 \mathrm{~K}$. Above $525 \mathrm{~K}$ the ${ }^{29} \mathrm{CO}$ signal drops again. In Ref. 9 TPD measurements on platinum foil in well-controlled vacuum experiments is shown. Desorption is seen between 350 and $575 \mathrm{~K}$ with moderate peaks at 415 and $530 \mathrm{~K}$. The peaks are not resolved within the noise in Fig. 5 and the desorption interval is shifted downwards about $50 \mathrm{~K}$. This is caused by the position of the thermocouple relative to the reactor and the heating element (Fig. 3) that results in a lower temperature at the thermocouple than in the reactor. This could be solved by integrating a temperature sensor on the reactor chip during microfabrication.

The microfabricated flow system with integrated capillary leak to a mass spectrometer offers minimum dead volume and corresponding maximum sensitivity and minimum delay in measured signals. This is a direct consequence of the miniaturization. The system has been used for TPD, but the specifications make it an ideal measurement system for observation of any fast concentration transients occurring in a gas phase experiment.

${ }^{1}$ K. F. Jensen, Chem. Eng. Sci. 56, 293 (2001).

${ }^{2}$ I. Chorkendorff and J. W. Niemantsverdriet, Concepts of Modern Catalysis and Kinetics (Wiley-VCH, New York, 2003).

${ }^{3}$ S. Bhatia, J. Beltramini, and D. D. Do, Catal. Today 7, 309 (1990).

${ }^{4}$ S. Thybo, S. Jensen, J. Johansen, T. Johannessen, O. Hansen, and U. J. Quaade, J. Catal. 223, 271 (2004).

${ }^{5}$ B. Kasemo, Rev. Sci. Instrum. 50, 1602 (1979).

${ }^{6}$ U. J. Quaade, S. Jensen, and O. Hansen (in preparation).

${ }^{7}$ A. M. Hynes, H. Ashraf, J. K. Bhardwaj, J. Hopkins, I. Johnston, and J. N. Shepherd, Sens. Actuators, A 74, 13 (1999).

${ }^{8}$ P. Lööf, B. Kasemo, S. Andersson, and A. Frestad, J. Catal. 130, 181 (1991).

${ }^{9}$ C. R. Henry, Surf. Sci. Rep. 31, 235 (1998). 